\section{Overexpression of p53 tumor suppressor gene in pterygia}

\begin{abstract}
Purpose To assess p53 gene expression in pterygia with and without recurrence. The pathogenesis of pterygium has not yet been determined. The most widely recognized etiologic factor is ultraviolet radiation, which leads to degeneration of the conjunctiva. However, pterygium was recently found to have several tumor-like characteristics. The p53 gene is a common marker for neoplasia, and is known to control cell cycle, cell differentiation and apoptosis. In this study we examined the expression of the p53 gene in primary pterygia with and without recurrence, searching for the pathogenesis of this very common lesion and for a prognostic factor for recurrence.
\end{abstract}

Methods Immunohistochemical staining using a monoclonal antibody to human p53 (DO-7) was performed on 13 consecutive patients with primary pterygia, four pterygia without recurrence and nine pterygia which recurred during a 12-month follow-up. As a control we used two specimens of normal conjunctiva.

Results Seven of the 13 pterygia specimens (54\%) were positive for abnormal p53 expression. There was no difference between the groups with and without recurrence. Two out of four pterygia $(50 \%)$ without recurrence and five out of nine $(55.5 \%)$ pterygia with recurrence were positive. No pathological staining was observed in the control specimens.

Conclusions In this study, abnormal p53 expression was found in pterygial epithelium, suggesting that pterygium could be a result of uncontrolled cell proliferation, and not as a degenerative lesion. There seems to be no connection between abnormal p53 expression and recurrence. Eye (2002) 16, 619-621. doi:10.1038/ sj.eye. 6700150

Keywords: pterygium; p53; neoplasia; degeneration; immunohistochemical staining
O Weinstein'1, G Rosenthal' ${ }^{1}, \mathrm{H}$ Zirkin², T Monos ${ }^{1}$, T Lifshitz ${ }^{1}$ and S Argov ${ }^{2}$

\section{Introduction}

Pterygium is a common, benign, fibrovascular lesion, originating from the bulbar conjunctiva. It is composed of epithelium and highly vascular, subepithelial, loose connective tissue.

The pathogenesis of pterygium is not clearly understood, the most widely recognised etiologic factor is ultraviolet radiation. ${ }^{1}$ Until recently, it was considered a degenerative disorder involving mainly the subepithelial tissue. Recent findings concerning common features in pterygium and neoplasia have been published, raising the possibility that pterygium is a neoplastic-like growth disorder. These features include recurrence following surgical excision, ultraviolet radiation as an etiologic factor, and common treatment modalities (antimetabolites, radiation). ${ }^{2,3}$

The p53 gene controls the cell cycle, is involved in DNA repair and synthesis, cell differentiation and apoptosis. ${ }^{4}$ Mutations in the p53 gene inactivate or alter its functions. These mutations are the most common genetic marker of human neoplastic growth.

This study was designed to investigate the expression of the p53 gene in primary pterygia, with and without recurrence. Our purpose was to determine whether pterygium is a result of an uncontrolled cell proliferation rather than a degenerative state, and to ascertain whether abnormal p53 expression can serve as a prognostic factor for the recurrence of pterygium following surgical excision.

\section{Materials and methods}

Formalin-fixed, paraffin-embedded tissues of pterygia were retrieved from the pathology archives of Soroka University Medical Center, Beer-Sheva, Israel. Thirteen consecutive patients who had undergone pterygium excision without mitomycin-C application, and had a postoperative follow-up of at least 12
'Department of Ophthalmology Soroka Medical Center Ben-Gurion University of the Negev Beer-Sheeva, Israel

Institute of Pathology Soroka Medical Center Ben-Gurion University of the Negev Beer-Sheva, Israel

Correspondence: O Weinstein, MD Department of Ophthalmology Soroka Medical Center Ben-Gurion University of the Negev

POB 151 Beer-Sheva, Israel

Tel: 97286400379

Fax: 97286403927

E-mail: orlyjm@

bezeqint.net 
months were selected. Four pterygia without recurrence and nine pterygia, which recurred during the follow-up period, were included in the study. (Since consecutive specimens were selected, the data presented here do not indicate the real recurrence rate.) As a control we used two specimens of normal conjunctiva (from eyes without pterygium). Sections $5 \mu \mathrm{m}$ thick were cut and attached to microscope slides, deparaffinized and dehydrated. Slides were heat treated for antigenic retrieval using citrate buffer followed by incubation with the anti-p53 antibody (DO-7, Zymed, South San Francisco, CA, USA).

The expression of the antigen was carried out using the avidine-biotin peroxidase (Vector Laboratories) method and AEC as chromogene. Results were evaluated by examining the sections in a high power field. Those with more than $10 \%$ of cells stained were considered positive.

\section{Results}

Seven out of the 13 pterygia specimens (54\%) were positive for abnormal p53 expression (Figure 1). There was no difference in staining between the groups with and without recurrence: two out of four pterygia $(50 \%)$ in the no recurrence group and five out of nine (55.5\%) pterygia in the recurrence group, were positive.

Staining was limited to the nuclei in the epithelial cells, mainly in the basal layer. No pathological staining was observed in the control specimens (Figure 2).

\section{Discussion}

In this study, we examined the expression of the p53 gene in primary pterygia to investigate the possibility

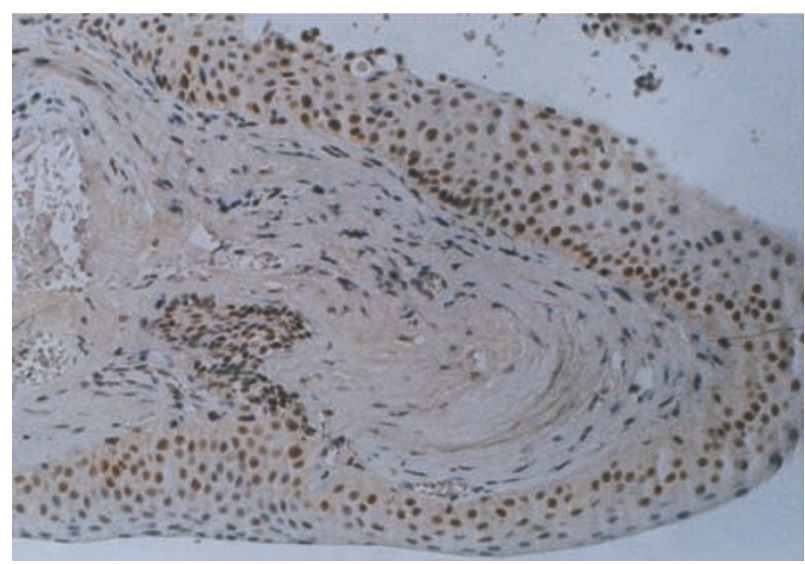

Figure 1 Immunohistochemical staining with monoclonal antibody DO-7 on section of pterygium showing positive staining (brown nuclei) for p53, mainly in the basal layer of the epithelium $(\times 320)$.

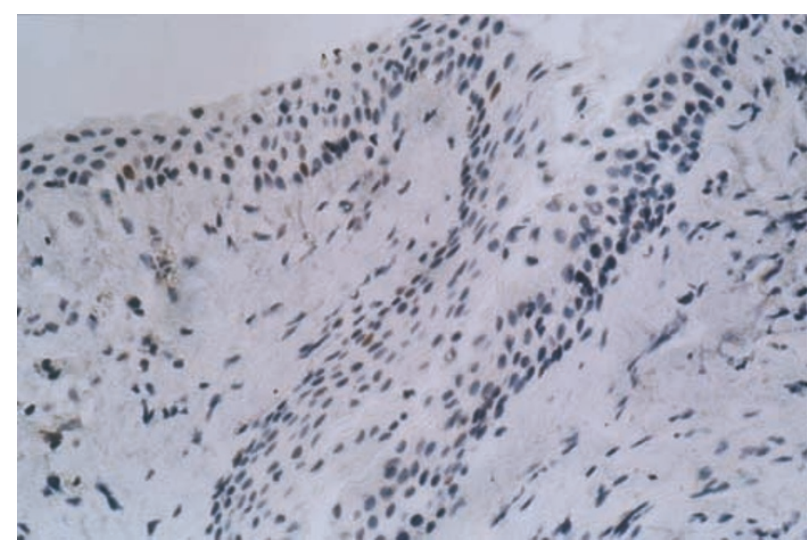

Figure 2 Immunohistochemical staining with monoclonal antibody DO-7 on section of normal conjunctiva showing negative staining for p53 $(\times 320)$.

that pterygium is a growth disorder resulting from uncontrolled cell proliferation rather than a degenerative process.

The $\mathrm{p} 53$ gene is located on the short arm of chromosome 17 and its main function is as a tumor suppressor gene. The gene controls the cell cycle, is involved in DNA repair and synthesis, cell differentiation and apoptosis. ${ }^{4}$ The gene stops the cell cycle when the genome is damaged, until the genome is repaired. If the damage is irreparable, the p53 gene leads to apoptosis. Mutations in the p53 gene inactivate or alter its functions. These mutations are the most common genetic marker of human neoplastic growth.

The p53 gene product, the p53 protein, is a nuclear phosphoprotein, which binds to the DNA. The protein can be identified by immunohistochemical staining, using a monoclonal antibody against it. Normal cells are negative for the stain, since the protein concentration is very low (due to the short half-life of the protein $(6-20 \mathrm{~min})$ ). In many types of neoplastic cells its concentration is higher and immunohistochemical staining for the protein will be positive.

As mentioned above, abnormal expression of p53 is the most common marker for malignant tumors in humans. The prevalence of p53 abnormal expression varies among tumor types, ranging from 0 to $60 \%$ in major cancers (eg 56\% in lung carcinoma, 50\% in colonic carcinoma, $44 \%$ in skin tumors, etc). ${ }^{5}$ Different classes of mutations occur in the p53 gene; threequarters of substitutions occur at G:C base pairs. ${ }^{4}$ However, there are a few reports of abnormal expression in benign tumors (benign phylloides tumor of the breast and benign breast biopsy specimens ${ }^{6}$ ). Although this finding is not common, it supports our results, since it is clear that pterygium is not a malignant tumor. 
Spandidos et $\mathrm{al}^{7}$ found that $60 \%$ of pterygia exhibited genetic alterations (loss of heterozygosity and microsatellite instability) which are common in tumor and premalignant cells. They concluded that there is a role for tumor suppressor genes and decreased fidelity in DNA replication and repair, in the development of pterygium. They also suggested that pterygium should be considered a benign neoplastic lesion.

Tam et $a l^{8}$ performed immunohistochemical staining on eight pterygia specimens using the pAb 240 monoclonal antibody and found three of them (37.5\%) to be positive for abnormal expression. Dushku and $\operatorname{Reid}^{9}$ found increased nuclear p53 in the limbal epithelium of pterygia, limbal tumors and pinguecula. They proposed that this might indicate the existence of p53 mutation in the cells as an early event in their development, probably as a result of UV radiation exposure. Onur et al, ${ }^{10}$ however, using immunohistochemical staining on 38 pterygia specimens, found that only $7.9 \%$ had a few p53 stained cells. In none of these studies was a control group used.

Recently, Chowers et al ${ }^{11}$ found p53 immunoreactivity in $50 \%$ of primary and recurrent pterygia, with no difference between pterygia that did and did not recur. Their conclusion was that a mutation in the p53 gene is not crucial for pterygium formation and recurrence.

Our finding of abnormal p53 expression in the epithelium of pterygia might imply that it contains transformed cells and there is failure in the regulation and control of the cell cycle. The cause of the transformation may be ultraviolet radiation, which is well known as a risk factor for various skin malignancies (eg squamous cell carcinoma) ${ }^{4}$ by its influence on the genetic material. Another possible reason for the mutation in the $\mathrm{p} 53$ gene may be hereditary; a familial pattern of pterygium has been previously reported. ${ }^{12-14}$

It is known that pterygium is a lesion with limited local invasion and inability to send metastases. Its cells, however, display genetic characteristics of a tumor. These might suggest that pterygium can be considered a benign neoplastic lesion. Further studies are needed to provide more information about the role of p53 in the pathogenesis of pterygium.

\section{References}

1 Mackenzie FD, Hirsh LW, Battistutta D, Green A. Risk analysis in the development of pterygia. Ophthalmology 1992; 99: 1056-1061.

2 Wong VA, Law FCH. Use of mitimycin C with conjunctival autograft in pterygium surgery in AsianCanadians. Opthalmology 1999; 106: 1512-1515.

3 Sanchez-Thorin JC, Rocha G, Yelin JB. Meta-analysis on the recurrence rates after bare sclera resection with and without mitimycin $C$ use and conjunctival autograft placement in surgery for primary pterygium. $\mathrm{Br} J$ Ophthalmol 1998; 82: 661-665.

4 Greenblatt MS, Bennett WP, Hollstein M, Harris CC. Mutation in the p53 tumor suppressor gene: clues to cancer etiology and molecular pathogenesis. Cancer Res 1994; 54: 4855-4878.

5 Harris CC, Holistein M. Clinical implications of the p53 tumor-suppressor gene. New England J Med 1993; 28: 1318-1328.

6 Younes M, Lebovitz RM, Bommer KE et al. P53 accumulation in benign breast biopsy specimens. Hum Pathol 1995; 26: 155-158.

7 Spandidos DA, Sourvinos H, Kiaris H, Tsamparlakis J Microsatellite instability and loss of heterozygosity in human pterygia. Br J Ophthalmol 1997; 81: 493-496.

8 Tam DT, Lim AS, Goh HS, Smith DR. Abnormal expression of the p53 tumor suppressor gene in the conjunctiva of patients with pterygium. Am J Ophthalmol 1997; 123: 404-405.

9 Dushku N, Reid TW. P53 expression in altered limbal basal cells of pigueculae, pterygia, and limbal tumors. Curr Eye Res 1997; 16: 1179-1192.

10 Onur C, Orhan D, Orhan M, Dizbay Sak S, Tulunay O, Irkee M. Expression of p53 protein in pterygia. Eur J Ophthalmol 1998; 8: 157-161.

11 Chowers I, Pe'er J, Zamir E, Livni N, Ilsar M. Proliferative activity and p53 expression in primary and recurrent pterygia. Ophthalmology 2001; 108: 985-988.

12 Brooth F. Heredity in one hundred patients admitted for excision of pterygia. Aust N Z J Ophthalmol 1985; 13: 5961.

13 Zhang JD. An investigation of aetiology and heredity of pterygium. report of 11 cases in a family. Acta Ophthalmol (Copenh) 1987; 65: 413-416.

14 Hecht F, Shoptaugh MG. Winglets of the eye: dominant transmission of early adult pterygium of the conjunctiva. J Med Genet 1990; 27: 392-394. 